\title{
Service Quality terhadap Word Of Mouth dan Dampaknya Terhadap Pembentukan Brand Image Perguruan Tinggi di Tangerang Raya
}

\author{
Tessa Handra
}

Universitas Multimedia Nusantara

tessa.handra@lecturer.umn.ac.id

\begin{abstract}
Metode yang dilakukan pada penelitian ini menggunakan tipe penelitian deskriptif dengan pendekatan kuantitatif. Sumber data yang digunakan adalah data primer, dan populasi pada penelitian ini adalah mahasiswa dan alumni yang kuliah di perguruan tinggi wilayah Tangerang Raya, dikarenakan jumlah mahasiswa dan alumni yang cukup besar dan kurang diketahui jumlah tepatnya, maka penulis menggunakan 100 sampel yang terdiri dari alumni dan mahasiswa di perguruan tinggi yang terletak di Tangerang Raya.Hasil dari penelitian ini adalah : 1). Service quality terhadap word of mouth signifikan akan tetapi pengaruhnya tidak terlalu besar hanya $21,3 \%$, 2). Word of mouth yang adalah sebagai variable penghubung pada penelitian ini, juga menunjukkan hasil yang signifikan terhadap Brand image, akan tetapi hanya menunjukan pengaruh yang juga kecil yaitu sebesar $24,7 \%, 3)$. Ketika dilkukan uji langsung antara service quality terhadap brand image, memiliki pengaruh yang sedikit lebih baik yaitu $28,1 \%$.
\end{abstract}

Kata kunci: Service Quality, Word Of Mouth, Brand Image

\section{PENDAHULUAN}

Brand image merupakan visi setiap institusi dilevelnya masing-masing, setiap orang mengatakan hal tertentu yang menyangkut sebuah layanan, maka harapannya adalah merek atau nama kita yang akan diingat.Dan terlebih lagi akan menimbulkan suatu image yang nimbulkan word of mouth yang positif. Word of mouth merupakan alat bagi institusi untuk mengkomunikasikan institusi kita dengan calon pelanggan atau calon pengguna jasa institusi. Yang mana berdasarkan pengalaman beberapa pelanggan jasa, word of mouth menjadi suatu sumber masukan yang sangat berharga bagi calon konsumen, dan memiliki efektifitas yang sangat akurat.

Salah satu variable untuk menciptakan word of mouth yang diharapkan oleh pelanggan dan konsumen, maka dibutuhkan kualitas pelayanan yang baik, yang mana kualitas pelayanan yang baik adalah output pelayanan yang sesuai dengan harapan konsumen dan pelanggan sesuai dengan pengorbanan konsumen dan pelanggan yang sudah disepakati dengan institusi, bahhkan penting bagi institusi dengan memeberikan kejutan pada konsumen dan pelanggannya agar pemasar dapat memasuki area kognitif konsumen dan pelanggan dengan harapan mereka dapat mengingat institusinya, dalam hal ini adalah perguruan tinggi. 


\section{TINJAUAN PUSTAKA}

\section{Brand Image}

Menurut Kotller dan Keller (2013) bahwa brand image sebagai persepsi mengenai sebuah merek sebagaimana direfleksikan oleh asosiasi merek yang terdapat dalam benak konsumen. Ditambahkan pula bahwa brand image menurut Henslowe (2008) adalah kesan yang di dapat menurut tingkatan dari pengetahuan dan pengertian akan fakta mengenai orang, produk, situasi. Objek yang dimaksud berupa orang, organisasi, kelompok orang atau lainnya yang tidak diketahui. Image merupakan pandangan atau persepsi serta terjadinya proses akumulasi dari amanat kepercayaan yang diberikan oleh individuindividu, akan mengalami suatu proses cepat atau lambat membentuk suatu opini publik yang lebih luas dan abstrak. Menurut Howard (2009) bahwa brand image sebagai gambaran total dari pikiran konsumen atau pelanggan sasaran terhadap produk atau merek. Sedangkan menurut Rangkuti (2012), brand image adalah sekumpulan asosiasi merek yang terbentuk dan melekat di benak konsumen.

Menurut Kottler dan Keller (2016) bahwa brand image terdiri dari komponen-komponen: a. Attributes (Atribut) Merupakan pendefinisian deskriptif tentang fitur-fitur yang ada dalam produk atau jasa. 1) Product related attributes (atribut produk) Didefinisikan sebagai bahan-bahan yang diperlukan agar fungsi produk yang dicari konsumen dapat bekerja. Berhubungan dengan komposisi fisik atau persyaratan dari suatu jasa yang ditawarkan, dapat berfungsi. 2) Non-product related attributes (atribut non-produk) Merupakan aspek eksternal dari suatu produk yang berhubungan dengan pembelian dan konsumsi suatu produk atau jasa. Terdiri dari: informasi tentang harga, kemasan dan desain produk, orang, per group atau selebriti yang menggunakan produk atau jasa tersebut, bagaimana dan dimana produk atau jasa itu digunakan. b. Benefits (Keuntungan) Nilai personal yang dikaitkan oleh konsumen pada atribut-atribut produk atau jasa tersebut. 1) Functional benefits : berhubungan dengan pemenuhan kebutuhan dasar seperti kebutuhan fisik dan keamanan atau pemecahan masalah. 2) Experiental benefits : berhubungan dengan perasaan yang muncul dengan menggunakan suatu produk atau jasa. Benefit ini memuaskan kebutuhan bereksperimen seperti kepuasan sensori. 3) Symbolic benefits : berhubungan dengan kebutuhan akan persetujuan sosial atau ekspresi personal dan self-esteem seseorang. Konsumen akan menghargai nilai-nilai prestise, eksklusivitas dan gaya fashion merek karena hal-hal ini berhubungan dengan konsep diri mereka. c. Brand Attitude (Sikap merek) Didefinisikan sebagai evaluasi keseluruhan atas suatu merek, apa yang dipercayai oleh konsumen mengenai merek-merek tertentu sejauh apa konsumen percaya bahwa produk atau jasa tersebut memiliki atribut atau keuntungan tertentu, dan penilaian evaluatif terhadap kepercayaan tersebut bagaimana baik atau buruknya suatu produk jika memiliki atribut atau keuntungan tersebut

\section{Service Quality}

Menurut Berry dan Zenthaml yang dalam Lupiyoadi (2006) berpendapat bahwa "Keberhasilan perusahaan dalam memberikan pelayanan yang berkualitas dapat ditentukan dengan pendekatan service quality yang telah dikembangkan oleh Parasuraman”. 
Wyckof dalam Wisnalmawati (2005) berpendapat bahwa "Kualitas jasa adalah tingkat keunggulan yang diharapkan dan pengendalian atas tingkat keunggulan untuk memenuhi keinginan pelanggan". Kotler dalam Wisnalmawati (2005: 156) berpendapat bahwa "Kualitas pelayanan harus dimulai dari kebutuhan pelanggan dan berakhir pada persepsi pelanggan". Hal ini berarti bahwa kualitas yang baik bukanlah berdasarkan persepsi penyediaan jasa, melainkan berdasarkan persepsi pelanggan.

Dimensi service quality Kualitas layanan dalam implementasi mempunyai beberapa dimensi, yang keberadaannya perlu diperhatikan dan diterapkan dengan baik agar badan usaha dapat unggul dalam bersaing. Menurut Zeithaml dan Bitner (2003) dalam Tjiptono dan Chandra (2005), ada lima dimensi kualitas layanan, yaitu reliability, responsiveness, assurance, empathy, dan tangibles, yang dapat dijelaskan sebagai berikut: a. Reliability (keandalan), berkaitan dengan kemampuan badan usaha untuk memberikan layanan yang akurat sejak pertama kali tanpa membuat kesalahan apapun dan menyampaikan layanan sesuai dengan waktu yang dijanjikan, akurat, dapat dipercaya, dan konsisten. b. Responsiveness (daya tanggap), berkaitan dengan kesediaan dan kemampuan karyawan untuk membantu para pelanggan dan merespons permintaan pelanggan, serta mengkonfirmasikan kapan saja layanan akan diberikan, dan memberikan layanan dengan tanggap. c. Assurance (jaminan), berkaitan dengan perilaku karyawan mampu menumbuhkan kepercayaan pelanggan terhadap badan usaha dan badan usaha bisa menciptakan rasa aman bagi para pelanggan.

Assurance juga berarti bahwa karyawan selalu bersikap sopan dan menguasai pengetahuan dan keterampilan yang dibutuhkan untuk menjawab setiap pertanyaan atau menangani masalah pelanggan. d. Empathy (kepedulian), berkaitan dengan kepedulian dan perhatian karyawan atau pemilik usaha kepada semua pelanggan, meliputi kemudahan melakukan hubungan atau komunikasi yang baik, perhatian pribadi, dan memahami kebutuhan para pelanggan. e. Tangibles (bukti fisik), berkaitan dengan penampilan fasilitas fisik, peralatan, karyawan, dan material-material yang dimiliki oleh badan usaha.

\section{Word of Mouth}

Definisi word of mouth menurut Word of mouth Marketing Association (WOMMA) Mix (2007) dalam Vandaliza (2007), adalah usaha pemasaran yang memicu konsumen untuk membicarakan, mempromosikan, merekomendasikan dan menjual produk/ merek kita kepada pelanggan lain. Sedangkan Khasali (2003), mengartikan word of mouth sebagai sesuatu hal yang dibicarakan banyak orang. Pembicaraan terjadi dikarenakan ada kontroversi yang membedakan dengan hal-hal yang biasa dan normal dilihat orang. Dengan demikian secara konseptual Wordofmouth yang Positif dapat dirumuskan sebagai komunikasi interpersonal antara dua bahkan lebih individu yang berefek pada pembentukan citra positif dari suatu produk atau layanan.

Menurut Harrison-Walker (2001) dan Brown (2005), komunikasi word of mouth dapat dikur dengan menggunakan indikator-indikator: 1) Fekuensi komunikasi WOM, 2) Kesenangan menceritakan pengalaman yang menyenangkan, 3) Meyakinkan orang lain untuk mengkonsumsi suatu produk atau jasa, dan 4) Kesenangan merekomendasikan kepada orang lain. Secara konseptual Word-ofmouth yang Positif dapat dirumuskan sebagai komunikasi interpersonal antara 
dua bahkan lebih individu yang berefek pada pembentukan citra positif dari suatu produk atau layanan (Agus Irwanto, dkk 2013). Wangenheim \& Bayón, 2007, dalam Sulivyo, dkk (2019) berpendapat bahwa dengan menggunakan komunikasi dari mulut ke mulut, konsumen yang merasa puas akan memberitahukan atau merekomendasikan suatu produk kepada teman-temannya untuk digunakan atau dibeli produk. Menurut Sernovitz (2009), terdapat lima dimensi atau elemen dasar word of mouth yang dikenal dengan 5T, yaitu: Talkers (pembicara), Topics (topik), Tools (alat), Talking part (partisipasi) dan Tracking (pengawasan), yaitu:

1. Talkers (pembicara), ini adalah kumpulan target dimana mereka yang akan membicarakan suatu merek biasa disebut juga influencer. Talkers ini bisa siapa saja mulai dari teman, tetangga, keluarga, dll. Selalu ada orang yang antusias untuk berbicara. Mereka ini yang paling bersemangat menceritakan pengalamannya.

2. Topics (topik), ini berkaitan dengan apa yang dibicarakan oleh talker. Topik ini berhubungan dengan apa yang ditawarkan oleh suatu merek. Seperti tawaran spesial, diskon, produk baru, atau pelayanan yang memuaskan. Topik yang baik ialah topik yang simpel, mudah dibawa, dan natural. Seluruh word of mouth memang bermula dari topik yang menggairahkan untuk dibicarakan.

3. Tools (alat), ini merupakan alat penyebaran dari topic dan talker. Topik yang telah ada juga membutuhkan suatu alat yang membantu agar topik atau pesan dapat berjalan. Alat ini membuat orang mudah membicarakan atau menularkan produk atau jasa perusahaan kepada orang lain.

4. Talking part (partisipasi), suatu pembicaraan akan hilang jika hanya ada satu orang yang berbicara mengenai suatu produk. Maka perlu adanya orang lain yang ikut serta dalam percakapan agar word of mouth dapat terus berlanjut.

5. Tracking (pengawasan), ialah suatu tindakan perusahaan untuk mengawasi serta memantau respon konsumen. Hal ini dilakukan agar perusahaan dapat mempelajari masukan positif atau negatif konsumen, sehingga dengan begitu perusahaan dapat belajar dari masukan tersebut untuk kemajuan yang lebih baik.

\section{METODELOGI PENELITIAN}

\section{Jenis Penelitian}

Metode yang dilakukan pada penelitian ini menggunakan tipe penelitian deskriptif dengan pendekatan kuantitatif. Metode penelitian kuantitatif, sebagaimana telah dikemukakan oleh Sugiyono (2015), "metode penelitian yang berdasarkan pada filsafat positivisme, digunakan untuk melihat pada populasi atau sample tertentu, pengumpulan data menggunakan instrumen penelitian, analisis data bersifat kuantitatif atau statistik, dengan tujuan untuk menguji hipotesis yang telah ditetapkan".

\section{Sumber Data}

Data pada penelitian ini menggunakan data primer, adapun menurut Sugiyono (2016) yang menyatakan bahwa data primer adalah sumber data yang langsung memberikan data kepada pengumpul data. Pengumpulan data primer yaitu pengumpulan data yang diperoleh secara langsung 
pada saat melakukan penelitian di lapangan, seperti hasil wawancara atau kuesioner yang dibagikan. Wawancara ataupun kuesioner berhubungan dengan Service Quality terhadap Word Of Mouth, dan Dampaknya Terhadap Pembentukan Brand Image Perguruan Tinggi di Tangerang Raya.

\section{Populasi dan Sampel}

Populasi pada penelitian ini adalah mahasiswa dan alumni yang kuliah di perguruan tinggi wilayah Tangerang Raya, dikarenakan jumlah mahasiswa dan alumni yang cukup besar dan kurang diketahui jumlah tepatnya, maka penulis menggunakan 100 sampel yang terdiri dari alumni dan mahasiswa di perguruan tinggi yang terletak di Tangerang Raya.

\section{HASIL PENELITIAN DAN PEMBAHASAN}

\section{UJi Validitas dan Reliabilitas}

\section{Variabel Service Quality}

\section{Tabel 1. Hasil Reliabilitas}

Reliability Statistics

\begin{tabular}{|r|r|}
\hline Cronbach's Alpha & N of Items \\
\hline .889 & 8 \\
\hline
\end{tabular}

Bagian ini mencantumkan hasil uji reliabilitas (koefisien reliabilitas) sebesar 0,889. Hasil ini diatas ketentuan yaitu 0,6 maka dinyatakan variabel service quality reliabel.

\section{Tabel 2. Hasil Total Korelasi}

Item-Total Statistics

\begin{tabular}{|l|r|r|r|r|}
\hline & $\begin{array}{c}\text { Scale Mean if } \\
\text { Item Deleted }\end{array}$ & $\begin{array}{c}\text { Scale Variance if } \\
\text { Item Deleted }\end{array}$ & $\begin{array}{c}\text { Corrected Item- } \\
\text { Total Correlation }\end{array}$ & $\begin{array}{c}\text { Cronbach's Alpha } \\
\text { if Item Deleted }\end{array}$ \\
\hline BUTIR_1 & 24.6800 & 31.068 & .909 & .851 \\
BUTIR_3 & 24.6800 & 31.068 & .909 & .851 \\
BUTIR_5 & 23.9700 & 39.747 & .269 & .905 \\
BUTIR_6 & 24.7300 & 31.189 & .797 & .861 \\
BUTIR_7 & 24.3100 & 31.691 & .700 & .872 \\
BUTIR_8 & 24.3000 & 35.000 & .672 & .876 \\
BUTIR_9 & 24.7700 & 31.755 & .719 & .870 \\
BUTIR_10 & 24.9800 & 37.192 & .353 & .905 \\
\hline
\end{tabular}

Corrected Item-Total Correlation, adalah korelasi Antara skor item dengan skor total item yang merupakan hasil dari uji validitas instrumen. Korelasi skor butir 1-10 terdapat 
dua butir pernyataan yang tidak valid yaitu butir pernyataan ke-2 dan ke-4 karena kolom Corrected Item-Total Correlation lebih dari 0,2, oleh karena itu kedua butir yang tidak valid tersebut, kami gugurkan.

\section{Variabel Word of Mouth}

\section{Tabel 3. Hasil Reliabilitas Variabel Word of Mouth}

Reliability Statistics

\begin{tabular}{|r|r|}
\hline Cronbach's Alpha & N of Items \\
\hline .905 & 10 \\
\hline
\end{tabular}

Bagian ini mencantumkan hasil uji reliabilitas (koefisien reliabilitas) sebesar 0,905. Hasil ini diatas ketentuan yaitu 0,6 maka dinyatakan variabel Word of Mouth reliabel.

\section{Tabel 4. Total Korelasi Variabel Word of Mouth}

Item-Total Statistics

\begin{tabular}{|l|r|r|r|r|}
\hline & $\begin{array}{c}\text { Scale Mean if } \\
\text { Item Deleted }\end{array}$ & $\begin{array}{c}\text { Scale Variance if } \\
\text { Item Deleted }\end{array}$ & $\begin{array}{c}\text { Corrected Item- } \\
\text { Total Correlation }\end{array}$ & $\begin{array}{c}\text { Cronbach's Alpha } \\
\text { if Item Deleted }\end{array}$ \\
\hline BUTIR_1 & 32.8100 & 46.196 & .855 & .884 \\
BUTIR_2 & 32.8700 & 47.124 & .599 & .901 \\
BUTIR_3 & 32.8100 & 46.196 & .855 & .884 \\
BUTIR_4 & 32.4500 & 48.876 & .735 & .892 \\
BUTIR_5 & 32.2000 & 54.061 & .348 & .911 \\
BUTIR_6 & 33.0600 & 53.148 & .386 & .910 \\
BUTIR_7 & 32.8600 & 44.849 & .777 & .888 \\
BUTIR_8 & 32.4500 & 48.876 & .735 & .892 \\
BUTIR_9 & 32.8600 & 44.849 & .777 & .888 \\
BUTIR_10 & 32.8700 & 47.124 & .599 & .901 \\
\hline
\end{tabular}

Corrected Item-Total Correlation, adalah korelasi Antara skor item dengan skor total item yang merupakan hasil dari uji validitas instrumen. Korelasi skor butir 1-10 valid karena kolom Corrected Item-Total Correlation lebih dari 0,2. 


\section{Variabel Brand Image}

\section{Tabel 5. Hasil Output Reliabilitas Brand Image}

Reliability Statistics

\begin{tabular}{|r|r|}
\hline Cronbach's Alpha & N of Items \\
\hline .852 & 10 \\
\hline
\end{tabular}

Bagian ini mencantumkan hasil uji reliabilitas (koefisien reliabilitas) sebesar 0,852. Hasil ini diatas ketentuan yaitu 0,6 maka dinyatakan variabel Brand Image reliabel.

\section{Tabel 6. Total Korelasi Brand Image}

Item-Total Statistics

\begin{tabular}{|l|r|r|r|r|}
\hline & $\begin{array}{c}\text { Scale Mean if } \\
\text { Item Deleted }\end{array}$ & $\begin{array}{c}\text { Scale Variance if } \\
\text { Item Deleted }\end{array}$ & $\begin{array}{c}\text { Corrected Item- } \\
\text { Total Correlation }\end{array}$ & $\begin{array}{c}\text { Cronbach's Alpha } \\
\text { if Item Deleted }\end{array}$ \\
\hline BUTIR_1 & 33.4000 & 31.919 & .636 & .831 \\
BUTIR_2 & 33.4400 & 33.784 & .587 & .836 \\
BUTIR_3 & 33.3200 & 33.250 & .741 & .824 \\
BUTIR_4 & 33.0600 & 34.057 & .675 & .830 \\
BUTIR_5 & 32.8000 & 36.646 & .435 & .848 \\
BUTIR_6 & 33.0700 & 33.965 & .705 & .828 \\
BUTIR_7 & 33.5200 & 36.495 & .363 & .854 \\
BUTIR_8 & 33.2000 & 33.879 & .634 & .832 \\
BUTIR_9 & 33.4400 & 32.168 & .503 & .848 \\
BUTIR_10 & 33.3900 & 34.119 & .430 & .852 \\
\hline
\end{tabular}

Corrected Item-Total Correlation, adalah korelasi Antara skor item dengan skor total item yang merupakan hasil dari uji validitas instrumen. Korelasi skor butir 1-10 valid karena kolom Corrected Item-Total Correlation lebih dari 0,2. 


\section{Uji Normalitas One Sample K-S}

\section{Tabel 7. Output Uni Normalitas One Sample K-S}

\begin{tabular}{|c|c|c|}
\hline \multicolumn{3}{|c|}{ One-Sample Kolmogorov-Smirnov Test } \\
\hline & & $\begin{array}{c}\text { Unstandardized } \\
\text { Residual }\end{array}$ \\
\hline \multicolumn{2}{|l|}{$\mathrm{N}$} & 100 \\
\hline \multirow[t]{2}{*}{ Normal Parameters ${ }^{\mathrm{a}, \mathrm{b}}$} & Mean & .0000000 \\
\hline & Std. Deviation & 60457140 \\
\hline \multirow[t]{3}{*}{ Most Extreme Differences } & Absolute & .075 \\
\hline & Positive & .053 \\
\hline & Negative & -.075 \\
\hline Test Statistic & & .075 \\
\hline Asymp. Sig. (2-tailed) & & $.181^{\mathrm{c}}$ \\
\hline
\end{tabular}

Berdasarkan output dengan uji statistik non-parametrik Kolmogorof-Smirnov (K-S) diperoleh nilai Sig. (2-tailed) sebesar 0,337 lebih besar dari 0,05 (0,181>0,05). Oleh sebab itu, Ho tidak dapat ditolak, sehingga dapat disimpulkan bahwa data residual terdistribusi normal.

\section{Uji Hipotesis}

\section{Hipotesis 1}

Tabel 8. Hasil Uji Hipotesis Service Quality

Coefficients $^{\mathrm{a}}$

\begin{tabular}{|c|c|c|c|c|c|c|}
\hline \multirow{2}{*}{\multicolumn{2}{|c|}{ Model }} & \multicolumn{2}{|c|}{ Unstandardized Coefficients } & \multirow{2}{*}{$\begin{array}{c}\begin{array}{c}\text { Standardized } \\
\text { Coefficients }\end{array} \\
\text { Beta }\end{array}$} & \multirow[b]{2}{*}{$\mathrm{t}$} & \multirow[b]{2}{*}{ Sig. } \\
\hline & & $\mathrm{B}$ & Std. Error & & & \\
\hline & (Constant) & 2.777 & .406 & & 6.842 & .000 \\
\hline & SQ & .190 & .088 & .213 & 2.153 & .034 \\
\hline
\end{tabular}

a. Dependent Variable: WOM

Pada tabel koefisien diatas menunjukan nilai signifikansi t sebesar 0,034 < 0,05 yang berarti Ho ditolak dan Ha diterima. Berdasarkan analisa diatas dapat diambil kesimpulan bahwa terdapat Pengaruh Service Quality Terhadap Word of Mouth Perguruan Tinggi di Tangerang Raya. 


\section{Hipotesis 2}

\section{Tabel 9. Hasil Uji Hipotesis Word of Mouth}

Coefficients $^{\mathrm{a}}$

\begin{tabular}{|c|c|c|c|c|c|c|}
\hline \multirow{2}{*}{\multicolumn{2}{|c|}{ Model }} & \multicolumn{2}{|c|}{ Unstandardized Coefficients } & \multirow{2}{*}{$\begin{array}{c}\begin{array}{c}\text { Standardized } \\
\text { Coefficients }\end{array} \\
\text { Beta }\end{array}$} & \multirow[b]{2}{*}{$\mathrm{t}$} & \multirow[b]{2}{*}{ Sig. } \\
\hline & & B & Std. Error & & & \\
\hline \multirow[t]{2}{*}{1} & (Constant) & 2.942 & .305 & & 9.649 & .000 \\
\hline & WOM & .207 & .082 & .247 & 2.528 & 013 \\
\hline
\end{tabular}

a. Dependent Variable: BI

Pada tabel koefisien diatas menunjukan nilai signifikansi t sebesar 0,013 < 0,05 yang berarti Ho ditolak dan Ha diterima. Berdasarkan analisa diatas dapat diambil kesimpulan bahwa terdapat Pengaruh Word of Mouth (yang berfungsi sebagai variable penghubung pada peelitian ini) Terhadap Service Quality Perguruan Tinggi di Tangerang Raya.

\section{Hipotesis 3}

\section{Tabel 10. Hasil Uji Hipotesis Service Quality Terhadap Brand Image}

Coefficients $^{\mathrm{a}}$

\begin{tabular}{|c|c|c|c|c|c|c|}
\hline \multirow{2}{*}{\multicolumn{2}{|c|}{ Model }} & \multicolumn{2}{|c|}{ Unstandardized Coefficients } & \multirow{2}{*}{$\begin{array}{c}\begin{array}{c}\text { Standardized } \\
\text { Coefficients }\end{array} \\
\text { Beta }\end{array}$} & \multirow[b]{2}{*}{$\mathrm{T}$} & \multirow[b]{2}{*}{ Sig. } \\
\hline & & $\mathrm{B}$ & Std. Error & & & \\
\hline \multirow[t]{2}{*}{1} & (Constant) & 2.745 & .334 & & 8.212 & .000 \\
\hline & SQ & .210 & .073 & .281 & 2.894 & .005 \\
\hline
\end{tabular}

a. Dependent Variable: BI

Pada tabel koefisien diatas menunjukan nilai signifikansi t sebesar 0,005 $<0,05$ yang berarti Ho ditolak dan Ha diterima. Berdasarkan analisa diatas dapat diambil kesimpulan bahwa terdapat Pengaruh Service Quality (X) Terhadap Brand Image Perguruan Tinggi di Tangerang Raya. 


\section{KESIMPULAN}

Service quality terhadap word of mouth signifikan akan tetapi pengaruhnya tidak terlalu besar hanya $21,3 \%$ pada tabel 8 dan kolom Beta, ini berarti setiap hal yang baik yang dilakukan oleh sebuah institussi yang menyediakan layanan yang baik, tidak menjadi bahasan yang dapat menjadi topik yang menyenengkan bagi pengguna jasa layanan pada perguruan tunggi di Tangerang Raya.

Word of mouth yang adalah sebagai variable penghubung pada penelitian ini, juga menunjukkan hasil yang signifikan terhadap Brand image, akan tetapi hanya menunjukan pengaruh yang juga kecil yaitu sebesar $24,7 \%$, ini dapat diasumsikan bahwa word of mouth yang baik kurang dapat berpengaruh besar terhadap brand image pada perguruan tinggi di Tangerang Raya.

Ketika dilkukan uji langsung antara service quality terhadap brand image, memiliki pengaruh yang sedikit lebih baik yaitu 28,1\% pada tabel 10 kolom Beta. Meskipun menunjukkan hasil yang signifikan, pengaruhnya juga masih kurang memuaskan.

\section{Saran}

1. Berdasarkan hasil tersebut, untuk penelitian selanjutnya perlu di gunakan variable lain guna menstimuli word of mouth sebagai variable penghubung seperti price, sehingga dapat berpengaruh yang lebih baik lagi terhadap brand image perguruan tinggi di Tangerang raya.

2. Bila sudah digunakan variable $X$ yang lainnya seperti price, maka perlu digaungkan juga bahwa kebijakan harga yang ditetapkan adalah sangat layak, sehingga populasi sasaran dapat menciptakan word of mouth yang maksimal dalam upaya terbentuknya brand image.

3. Variabel X yang disarankan, diharapkan juga memiliki pengaruh langsung yang sangat besar dalam pembentukan brand image yang diharapkan. 


\section{REFERENSI}

Agus Irwanto, dkk 2013. Analisis Pengaruh Kualitas Produk dan Strategi Harga terhadap Kepuasan Pelanggan, dan Pengaruhnya pada Terbentuknya Word-of-mouth di Perumahan Madani Group Jabodetabek, Jurnal Aplikasi Manajemen, volume 11.

Freddy Rangkuti. 2012. Studi Kelayakan Bisnis \& Investasi. Gramedia Pustaka Utama. Jakarta. Henslowe, P. 2008. Public Relation, A Practical Guide to the Basics. Kogan Page Ltd, USA.

Harrison, L., Jean -Walker. 2001. The Measurement of Word of Mouth Communication And An Investigation of Service Quality And Customer Commitment As Potential Antecedents", Journal of Service Research, Vol. 4, No. 1, pp. 60-75.

Kotler, Philip., Keller, Kevin L. (2013). Manajemen Pemasaran, Jilid Kedua, Jakarta: Erlangga.

Kotler, Philip and Keller, Kevin Lane. (2016). Marketing Management -15/E. Essex, England: Pearson Education.

Lupiyoadi dan Hamdani, 2006. Manajemen Pemasaran jasa Edisi kedua. Penerbit Salemba Empat: Jakarta.

Sernovitz. 2009. Word of Mouth Marketing. Jakarta: Gramedia Pustaka Utama.

Sugiyono. 2015. Metode Penelitian Kuantitatif. Kualitatif dan R\&D. Bandung Alfabeta.

Sugiyono. 2016. Metode Penelitian Kuantitatif. Kualitatif dan R\&D. Bandung Alfabeta.

Sulivyo Lod, et.al 2019. The Effectiveness of Holistic Marketing and Word-of-Mouth Communication on Purchasing Decision at Pt Asuransi Central Asia Branch Office of Tiang Bendera West Jakarta: International Journal of Multicultural and Multireligious Understanding, Volume 6: 187-199.

Sulivyo Lod, Tessa Handra 2020. The Effect of Trust-Worthiness, Expertness, Similarity, and Attractiveness on Brand Attitude and Attitude towards Advertisements As Mediation Variables in Brand X: Russian Journal of Agricultural and Socio-Economic Sciences (RJOAS): 10(106) 52-59.

Tjiptono dan G. Chandra, 2005, Service, Quality, \& Satisfaction, Yogyakarta: Andi

Vandaliza, V. 2007. Studi Kepuasan Pelanggan Sebagai Langkah Strategik Dalam Membangun Minat Mereferensikan. Tesis.Semarang: Program Studi Magister Manajemen, Pascasarjana Universitas Diponegoro.

Wisnalmawati, 2005, Pengaruh persepsi dimensi kualitas layanan terhadap niat pembelian ulang. Jurnal ekonomi dan bisnis, No. 3 jilid 102005. 